\title{
Distribution of eight serotypes of Ureaplasma urealyticum in cases of non-gonococcal urethritis and of gonorrhoea, and in healthy persons
}

\author{
P. PIOT \\ Laboratory of Bacteriology, Institute of Tropical Medicine, Antwerp, Belgium
}

\section{Summary \\ The isolation rate of Ureaplasma urealyticum was 57 per cent. from 47 patients with non-gonococcal urethritis, 40 per cent. from forty patients with gonorrhoea, 47 per cent. from healthy sailors, and 53 per cent. from healthy students and laboratory technicians. No difference in distribution of eight serotypes among 45 isolates from these groups was demonstrated and no particular serotype could be correlated with disease symptoms.}

\section{Introduction}

Since Shepard (1954) described the 'T-strain' of mycoplasma, numerous attempts have been made to provide evidence for its aetiological role in nongonococcal urethritis (NGU). Many reports suggest a causal relationship (Shepard, Alexander, Lunceford, and Campbell, 1964; Csonka, Williams and Corse, 1966; Holmes, Johnson, Floyd and Kvale, 1967) but other, carefully controlled studies do not support this view (Ingham, MacFarlane, Hale, Selkon, and Codd, 1966; Black and Rasmussen, 1968; Jansson, Lassus, Stubb, and Tuuri, 1971; Haas, Dorfman, and Sacks, 1971). Extended reviews of these and other studies have been published recently by Freundt (1974), Morton (1975), and Dunlop (1975).

Few surveys, however, deal with the serological diversity of Ureaplasma urealyticum (Shepard, Lunceford, Ford, Purcell, Taylor-Robinson, Razin, and Black, 1974). Ford (1967), Purcell, Chanock, and Taylor-Robinson (1969), Lin, Kendrick, and Kass (1972), and Black (1973) failed to demonstrate any correlation between particular serotypes and disease, but the small number of cases does not allow definite conclusions.

Received for publication December 12, 1975

Address for reprints: Dr. P. Piot, M.D., Institute of Tropical Medicine, Nationalestraat 155, B-2000 Antwerp, Belgium
The purpose of this study was (1) to determine the incidence of $U$. urealyticum in patients with nongonococcal urethritis (NGU) as compared with patients with gonococcal urethritis and healthy subjects; (2) to compare the distribution of serotypes of $U$. urealyticum isolated from these persons.

\section{Material and methods}

Study population

Patients who attended the clinic of the Institute of Tropical Medicine, Antwerp, between March, 1975, and October, 1975, were divided into three groups:

(1) Men presenting because of NGU (47 subjects, average age 26 years). These patients suffered from a mucopurulent discharge, which contained more than ten leucocytes per microscopic field $(\times 400)$ in 32 cases, and five to ten leucocytes per microscopic field in the remaining fifteen cases. Microscopical examination and culture failed to reveal Neisseria gonorrhoeae or Trichomonas vaginalis.

(2) Men with gonorrhoea proved by microscopy and culture (40 subjects, average age 25 years).

(3) A first control group consisted of seamen without urethral symptoms consulting for a health certificate and men without signs of urethritis consulting because of fear of venereal disease after sexual exposure (34 subjects, average age 24 years). No leucocytes or $T$. vaginalis were found on microscopic examination and cultures for gonococci remained negative. These three groups mainly comprised seamen and immigrant workers.

(4) A second control group consisted of medical students and laboratory technicians with no history or sign of urethritis ( 32 subjects, average age 25 years).

\section{Specimen collection}

From the first three groups, specimens were collected by intraurethral scraping with a platinum loop. From Group 4 a first voided urine specimen $(30 \mathrm{ml})$ was centrifuged at 3000 r.p.m. for $15 \mathrm{~min}$. and the sediment cultured. All specimens were taken in the laboratory and were immediately incubated.

Culture methods

The following media were used: 
(1) Enrichment broth, consisting of proteose peptone No. 3 (Difco) 1.5 per cent., $\mathrm{NaCl} 0.5$ per cent., fresh yeast extract (baker's yeast) $2 \cdot 5$ per cent., fresh horse plasma 12 per cent., vancomycin $3 \mu \mathrm{g} / \mathrm{ml}$., colistin 7.5 $\mu \mathrm{g} . / \mathrm{ml}$., nystatin $12.5 \mu \mathrm{g} . / \mathrm{ml}$. (VCN-inhibitor, Baltimore Biological Laboratory), trimethoprim lactate $3 \mu \mathrm{g} . / \mathrm{ml}$; phosphate buffer $\left(\mathrm{KH}_{2} \mathrm{PO}_{4}-\mathrm{Na}_{2} \mathrm{HPO}_{4}\right) 20$ per cent., $\mathrm{pH} 6 \cdot 2$.

(2) A selective medium for the growth of Ureaplasma (L-medium). The medium as above, but with the addition of ion agar No. 2 (Oxoid) $1 \cdot 1$ per cent. and lincomycin at a concentration of $15 \mu \mathrm{g} . / \mathrm{ml}$. (Braun, Klein, and Kass 1970).

(3) Mycoplasma agar base (Oxoid) and Mycoplasma supplement-G (Oxoid), with the same combination of antibiotics as in the first medium, was used for the culture of 'classic Mycoplasmas'.

Each specimen was incubated in the enrichment broth at $37^{\circ} \mathrm{C}$. in a candle extinction jar (Haas and others, 1971).

After 16 to $18 \mathrm{hrs} 0.1 \mathrm{ml}$. of the broth culture was inoculated on to the solid media. These were incubated for $48 \mathrm{hrs}$ at $37^{\circ} \mathrm{C}$. in a candle extinction jar.

Plates for 'classic' mycoplasmas were observed under a microscope at a magnification of 100 without previous staining. They were identified by the growth inhibition test, using antisera prepared against Mycoplasma hominis and Mycoplasma fermentans (National Institute of Allergy and Infectious Diseases, Bethesda, USA). Colonies growing on the L-medium were identified as $U$. urealyticum on the basis of their colonial morphology, their ability to utilize urea by a direct test (Shepard, 1973), and their resistance to $15 \mu \mathrm{g} . / \mathrm{ml}$. lincomycin (Braun and others, 1970). 45 isolates were purified and lyophilized in the enrichment broth.

\section{Serotyping}

The growth inhibition test as described by Black (1973) was used under the following conditions:

The L-medium was preheated at $37^{\circ} \mathrm{C}$ for 60 minutes and one drop of $0.01 \mathrm{ml}$ of an overnight Ureaplasma culture $\left(10^{4}-10^{5}\right.$ colony-forming units $/ \mathrm{ml}$.) was distributed on the agar plate by the running drop technique; $0.025 \mathrm{ml}$ antiserum was applied in a $4 \mathrm{~mm}$ well and the plates were incubated at $32^{\circ} \mathrm{C}$. in atmospheric air with 10 per cent. $\mathrm{CO}_{2}$ for 48 hours. The plates were examined under a stereomicroscope after application of a mixture of 1 per cent. urea and 0.8 per cent. manganese sulphate (Shepard, 1973). Zones of inhibition of more than $0.5 \mathrm{~mm}$ were measured from the edge of the well into the beginning of growth. In addition, reference strains against the eight serotypes of $U$. urealyticum were tested (Shepard and others, 1974). Rabbit antisera against these reference strains were obtained from Dr. M. C. Shepard.

\section{Results}

The results of the isolation of mycoplasmas from urethral specimens are shown in Table I. All isolates of the classic colony type proved to be $M$. hominis.

Patients with NGU showed the greatest incidence of $U$. urealyticum ( 57 per cent.), one quarter of which occurred in association with $M$. hominis. $U$. urealyticum was isolated in 40 per cent. of forty patients with gonorrhoea, one-third being associated with $M$. hominis. This difference is not significant. The isolation rates of $U$. urealyticum in the two control groups are also similar (47 and 53 per cent.), but $M$. hominis was demonstrated in only 9 per cent. of the students and technicians, as compared with 24 per cent. in the other control group.

There was no correlation between the occurrence of $U$. urealyticum and the amount of urethral discharge or the number of leucocytes in it.

31 strains could be typed with the eight standard sera; one of the isolates of the control group contained at least two serotypes (II and VI). The distribution of the eight serotypes among the three groups was similar and in each group about one-third of the strains could not be typed with the available antisera. No single serotype was related to NGU or other pathological conditions of the male urethra (Table II).

TABLE I Isolation rates of mycoplasmas from patients and controls

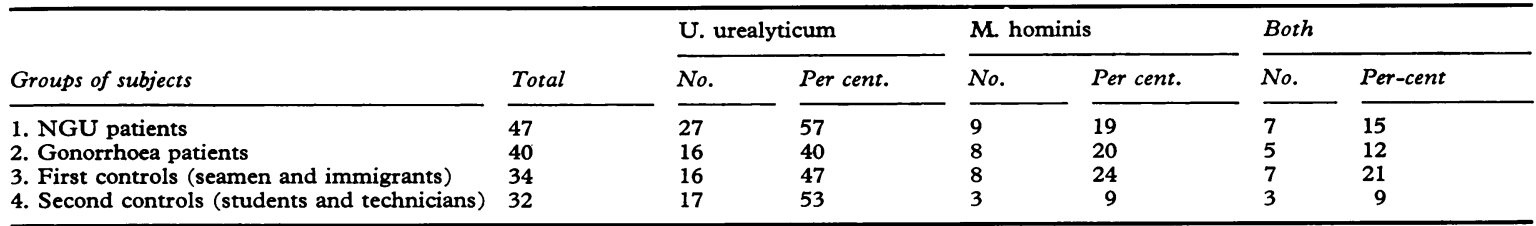

TABLE II Serotyping of Ureaplasma urealyticum isolated from the male urethra

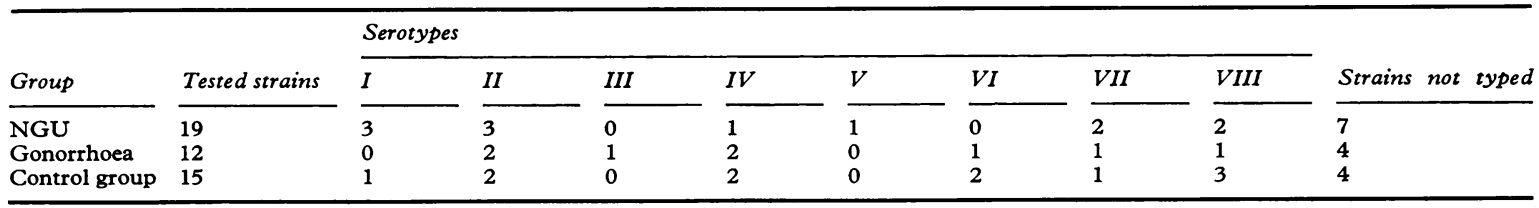




\section{Discussion}

The isolation rates of $U$. urealyticum in this study are comparable with those of earlier investigators (Ingham and others, 1966; Black and Rasmussen, 1968; Fowler and Leeming, 1969; Jansson and others, 1971). Unfortunately, at the time of the present investigation, cultures or serological tests for Chlamydia were not performed and no distinction between Chlamydia-linked NGU and non-chlamydial NGU was made.

The incidence in the group of healthy students and laboratory technicians did not differ significantly from the other control group, which was expected to be closest to the two patient groups as regards social background and sexual activity. Moreover, the mycoplasmas were isolated from urine, which is said to provide lower isolation rates (Black and Rasmussen, 1968). The addition of VCNT-inhibitor provides an excellent selective medium for the isolation of mycoplasmas from genital exudates, including the female genital tract (unpublished observations). Under appropriate conditions the growth-inhibition test proved to be suitable for the serological classification of human ureaplasmas. Although the number of typed strains in the present series is small, additional evidence is presented that there is no aetiological relationship between any particular serotype of $U$. urealyticum and NGU. This study could not confirm the high incidence of serotypes I and III in NGU reported by Black (1973) in ten isolates. In one isolate, two serotypes could be distinguished. The immunofluorescence serotyping technique (Black, 1970) might have revealed more multiple serotypes in the ureaplasma isolates.

The present serological data indicate that strains of similar types can be isolated from different countries such as Denmark, the U.S.A., and Belgium.

There appeared to be at least nine serotypes of $U$. urealyticum in our series; antisera prepared against the 'untyped' strains would reveal additional serotypes, but without adding anything new to our knowledge of the role of $U$. urealyticum in NGU.

At present definite evidence of the aetiological role of $U$. urealyticum in NGU can be obtained only by the inoculation of pure cultures into volunteers (Jansson and others, 1971). Rodermund and Jänsch (1974) mentioned an experiment of autoinoculation provoking NGU, but presented no information about the inoculum size, the serotype of the strain, and the clinical history.

Further studies should deal not only with the role of different micro-organisms in NGU, but also with the local defence mechanisms of the urethral mucosa.
We wish to thank Prof. E. A. Freundt, FAO/WHO International Reference Centre for Animal Mycoplasmas, Aarhus, for providing reference strains of $U$. urealyticum and antisera against $M$. hominis and $M$. fermentans, and Dr. M. C. Shepard, Naval Medical Field Research Laboratory, Camp Lejeune, for supplying the antisera against the serotypes of $U$. urealyticum.

\section{References}

BLACK, F. T. (1970) 'Fifth Int. Congr. Infect. Dis'. vol. 1, p. 407

- (1973) Appl. Microbiol., 25, 528

and RASMUSSEN, O. G. (1968) Brit. f. vener. Dis., 44, 324

Braun, P., Klein, J. O., and Kass, E. M. (1970) $A p p l$. Microbiol., 19, 62

CsonkA, G. W., Williams, R. E. O., and Corse, J. (1966) Lancet, 1, 1292

Dunlop, E. M. C. (1975) In 'Recent Advances in Sexually Transmitted Diseases', ed. R. S. MORTON and J. R. W. HARRIS, p. 267. Churchill Livingstone, London

FoRD, D. K. (1967) Ann. N.Y. Acad. Sci., 143, 501

FowlER, W., and LeEming, R. J. (1969) Brit. F. vener. Dis., 45, 287

FreUNDT, E. A. (1974) Path. et Microbiol., 40, 155

HaAs, H., Dorfman, M. L., and SACKS, T. G. (1971) Brit. F. vener. Dis., 47, 131

Holmes, K. K., Johnson, D. W., Floyd, T. M., and Kvale, P. A., (1967) f. Amer. med. Ass., 202, 467

INGHAM, H. R., MAcFaRLANE, W. V., HaIE, J. H., Selkon, J. B., and CODD, A. A. (1966) Brit. F. vener Dis., 42, 269

Jansson, E., Lassus, A., StubB, S., and TuURI, S. (1971) Ibid., 47, 122

LiN, J.-S. L., Kendrick, M. I., and Kass, E. H. (1972) f. infect. Dis., 126, 658

MORTON, R. S. (1975) In 'Recent Advances in Sexually Transmitted Diseases', ed. R. S. MoRTon and J. R. W. HARRIS, p. 257. Churchill Livingstone, London

PuRCell, R. H., Chanock, R. M., and TALyoR-Robinson, D. (1969) In 'The Mycoplasmatales and the L-phase of Bacteria', ed. L. HAYFLICK, p. 221. AppletonCentury Crofts, New York

RODERMUND, O.-E., and JÄNSCH, H.-H. (1974) Hautarzt, 25, 597

ShEPARD, M. C. (1954) Amer. F. Syph., 38, 113 (1973) f. infect. Dis., 127, S22

-, AlEXANDER, C. E., LuNCEFORD, C. D., and CAMPBeLL P. E. (1964) f. Amer. med. Ass., 188, 729

, LunCerord, C. D., Ford, D. K., PuRCell, R. H., TAYLOR-Robinson, D., Razin, S., and BLACK, F. T. (1974) Int. F. syst. Bact., 24, 160 